\title{
Optimum technological modes of ion implantation and subsequent annealing for formation of thin nanosized silicide films
}

\author{
Ilkhom Bekpulatov", Ilkhom Turapov, Sevara Abraeva, and Jakhongir Normuminov \\ Tashkent State Technical University, Tashkent, Uzbekistan
}

\begin{abstract}
Using the methods of electron spectroscopy and slow electron diffraction, we studied the processes of the formation of nanosized metal silicide films in the near-surface region of $\mathrm{Si} \mathrm{(111)} \mathrm{and} \mathrm{Si}$ (100) during low-energy implantation of $\mathrm{Ba}$ ions and alkaline elements. The optimal technological modes of ion implantation and subsequent annealing for the formation of thin nanoscale films of silicides were determined. The type of surface superstructures of thin silicide films has been established.
\end{abstract}

\section{Introduction}

The processes of formation of nanoscale films of metal silicides in the near-surface region of Si (111) and Si (100) during low-energy implantation of $\mathrm{Ba}^{+}$ions and alkaline elements have been studied by electron spectroscopy and low-energy electron diffraction. The optimal technological modes of ion implantation and subsequent annealing for the formation of thin nanosized silicide films have been determined. The type of surface superstructures of thin silicide films has been established.

In recent years, considerable attention has been paid to the formation of thin monocrystalline silicide films of $\mathrm{Li}, \mathrm{K}, \mathrm{Na}, \mathrm{Rb}, \mathrm{Cs}, \mathrm{Ba}$ in silicon in connection with the prospect of their use in thermogenerators, thermoelectric batteries, thermal radiation receivers, various sensors, as elements of functional integrated circuits for high-speed micro- and nanoelectronic devices, as well as plasmon waveguides for optoelectronic devices.

\section{Methods}

The main methods for forming silicide films are thermal deposition, solid-phase, and molecular beam epitaxy. Although the first two methods are generally available, they are rarely used recently due to the low quality of the films obtained. Molecular beam epitaxy allows to obtain very thin films with good quality but requires expensive equipment [1-4]. In this work, to obtain thin silicide films, a method is proposed for the implantation of $\mathrm{Li}$, $\mathrm{K}, \mathrm{Na}, \mathrm{Rb}, \mathrm{Cs}, \mathrm{Ba}$ ions in $\mathrm{Si}$ under ultrahigh vacuum conditions $\left(\sim 10^{-7} \mathrm{~Pa}\right)$. The experimental technique is described in [5].

\footnotetext{
*Corresponding author: bekpulatov85@rambler.ru
} 


\section{Results and Discussion}

Systematic studies of changes in the Si surface region occurring during the implantation of $\mathrm{Li}, \mathrm{K}, \mathrm{Na}, \mathrm{Rb}, \mathrm{Cs}$, and $\mathrm{Ba}$ ions with different energies and radiation doses have been carried out by the methods of low-energy electron diffraction Auger electron spectroscopy, and high-resolution scanning electron microscopy. Based on these studies, we have determined the optimal modes of ion implantation (type, energy, dose) and subsequent thermal annealing (temperature, time) for the formation of thin nanosized films of metal silicides (Table).

Table 1 shows the modes of formation and types of surface superstructures of Ba silicides and alkaline elements formed after short-term annealing of silicon samples implanted with ions with an energy of $1 \mathrm{keV}$ [6-12]. Note that we also observed the indicated surface superstructures after annealing of samples implanted with high-energy ions $\left(E_{0}=2-5 \mathrm{keV}\right)$. The only difference was that the formation of surface structures required a longer (the more, the higher the ion energy) annealing at the corresponding temperatures [13-20].

Table 1. Optimal modes for the formation of thin nanosized films barium silicides and alkaline elements

\begin{tabular}{|c|c|c|c|c|c|c|}
\hline Silicide type & \multirow{2}{*}{$\mathrm{LiSi}$} & $\mathrm{NaSi}$ & $\mathrm{KSi}$ & $\mathrm{RbSi}$ & $\mathrm{CsSi}$ & $\mathrm{BaSi}$ \\
\hline Options & 111 & 100111 & 100 & 100111 & 100111 & 100111 \\
\hline Initial Si structure & $0.5-5$ & $0.5-5$ & $0.5-5$ & $0.5-5$ & $0.5-5$ & $0.5-5$ \\
\hline Ion energy, keV & $90-1000$ & $600-700$ & $800-850$ & $800-850$ & $500-600$ & $800-900$ \\
\hline Annealing temperature, K & $90-110$ & $45-100$ & $35-95$ & $30-90$ & $40-90$ & $35-85$ \\
\hline Silicide thickness, $\AA$ & $50-1 \times 4$ & $4 \times 41 \times 1$ & $2 \times 1$ & $2 \times 42 \times 2$ & $2 \times 82 \times 2$ & $2 \times 21 \times 1$ \\
\hline Superstructure type & $4 \times 4$ & 3543 & 49 & 3542 & 3930 & 3843 \\
\hline Electron energy E, $\mathrm{eV}$ & 42 & 1100 & 1200 & 1200 & 1000 & 1300 \\
\hline $\begin{array}{c}\text { Recovery temperature } \\
\text { initial structure, } \mathrm{K}\end{array}$ & 1400 & &
\end{tabular}

Depending on the type of the initial face of the silicon surface and the type of implanted ions of alkaline and alkaline-earth elements, the formation of various types of surface superstructures is observed. We have found that starting from a certain dose of implantation of low-energy ions (which depends on the energy and type of ions), amorphization of the near-surface region of $\mathrm{Si}(111)$ and $\mathrm{Si}(100)$ is observed. The critical doses of $\mathrm{Si}$ amorphization have been determined. It was also found that starting from doses exceeding the dose of amorphization, partial formation of new chemical compounds is observed. Subsequent short-term thermal annealing of ion-implanted $\mathrm{Si}$ samples leads to the formation of thin nanosized silicide films with new surface structures: $\mathrm{Si}$ (111)-4x4Li, Si (111)-2x2Rb, Si (111)-1x1Na, Si (111)-2x2Cs, Si (111)-1x1Ba, Si (100)-2x2Ba, Si (100)$4 \times 4 \mathrm{Na}$, Si (100)-2x4Rb, Si (100)-2x1K, Si (100)-2x8Cs. The appearance of new surface superstructures is an additional confirmation of the formation of thin silicide films with a single crystal structure. 


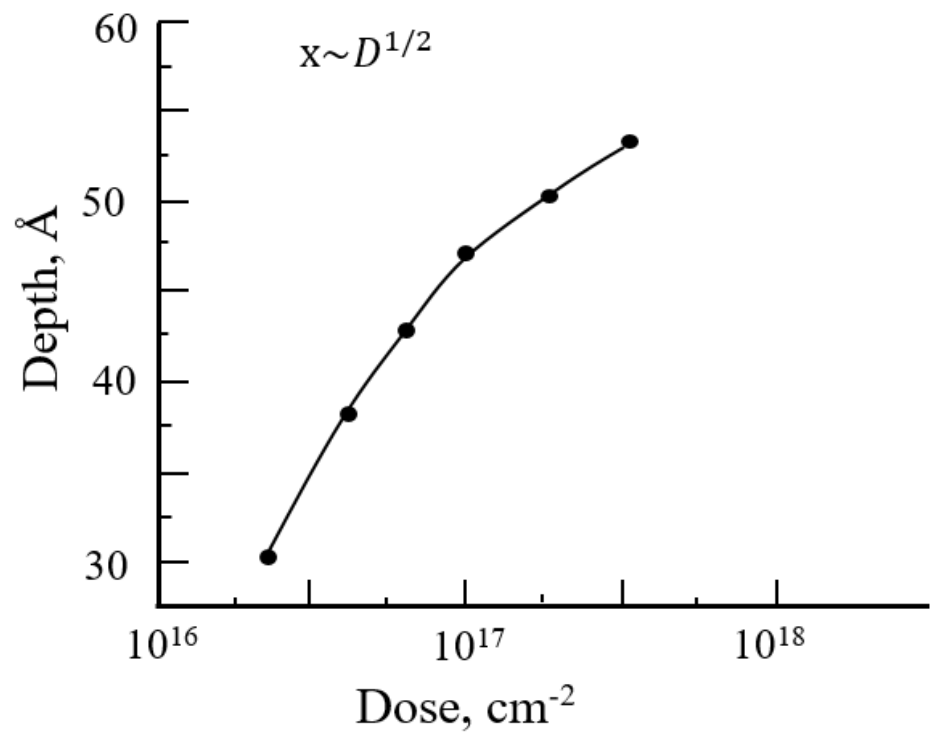

Fig.1. Dependences of the thickness of the RbSi silicide film $\mathrm{x}$ on the dose of ions D.

Thus, as a result of ion implantation and subsequent annealing, films of the following silicides are formed in the near-surface region of $\mathrm{Si}$ : $\mathrm{LiSi}, \mathrm{KSi}, \mathrm{RbSi}, \mathrm{CsSi}, \mathrm{NaSi}$, and $\mathrm{BaSi}$.

Experimental measurements of the thickness of silicide films showed that it grows with an increase in the energy of implanted ions; at fixed ion energy, it also grows with an increase in the dose, approximately as $\mathrm{D}^{1 / 2}$ (Fig. 1). Figure 1 shows the dependences of the thickness of the RbSi silicide film on the dose of $\mathrm{D}$ ions.

Measurement of the maximum range of $\mathrm{Ba}^{+}$ions and alkaline elements in $\mathrm{Si}$ (111) on the energy of implanted ions showed that the range of ions increases almost linearly with increasing $\mathrm{E}_{0}$ (Fig. 2).

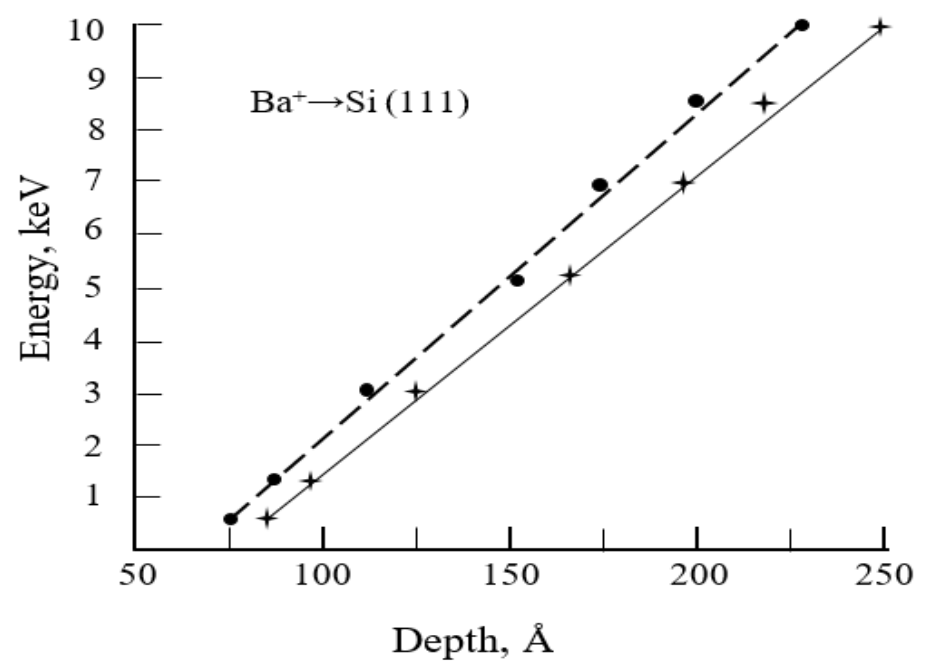

Fig.2. Dependences of the maximum range on the energy of the implanted barium ions $\mathrm{E}_{0}$ (solid curve is experiment, dashed curve is calculation). 
It is shown that the implantation of $\mathrm{Na}^{+}, \mathrm{Rb}^{+}, \mathrm{Cs}^{+}, \mathrm{Li}^{+}$ions with $\mathrm{E}_{0}=1 \mathrm{keV}$, with a large dose in $\mathrm{Si}(111)$ and subsequent short-term heating at $600,800,500,900 \mathrm{~K}$, respectively, leads to the formation of silicide films in the near-surface layer with the following structures: $\mathrm{Si}$ (111)-4x4 Na; Si (111)-2x2 Rb; Si (111)-4x4Cs; Si (111)-4x4 Li, and heating of Si (100) samples implanted with $\mathrm{Na}^{+}, \mathrm{Rb}^{+}, \mathrm{K}^{+}$, and $\mathrm{Cs}^{+}$ions with $\mathrm{E}_{0}=1 \mathrm{keV}$ leads to the formation of silicides with surface superstructures: Si (100)-4x4Na; Si (100)-2x4Rb; Si (100)-2x1K; Si (100)-2x8Cs.

It has been established in the course of studies of changes in the specific electrical conductivity of the n-type $\mathrm{Si}$ (111) surface during the implantation of $\mathrm{Ba}^{+}, \mathrm{Na}^{+}$, and $\mathrm{Li}^{+}$ions with an energy of $1 \mathrm{keV}$ with various doses that the implantation of ions (regardless of the type of ions) up to a dose of $8 \cdot 10^{14} \mathrm{~cm}^{-2}$ is practically not led to a change in $\sigma$ (Figure 3 ) [4]. The result is probably associated with deep penetration due to the channeling of implanted ions and their small contribution to the surface conductivity. It should be noted that the implantation of $\mathrm{Ba}^{+}$ions and alkaline elements with a dose of $\sim 10^{14} \mathrm{~cm}^{-2}$ leads to an increase in the concentration of electrons at donor levels and to the beginning of the splitting of donor levels, which should result in an increase in $\sigma$ [4]. However, at these doses, the Si (111) surface region is significantly disordered, which leads to a decrease in the surface electrical conductivity, the latter compensating for the contribution of an increase in donor concentration to an increase in $\sigma$. An effective and similar mechanism is evidenced by the minima on the dose dependences of $\sigma$ (Figure 3). With an increase in the dose of implanted ions, a sharp increase in $\sigma$ is observed up to $\mathrm{D}=10^{17} \mathrm{~cm}^{-2}$.

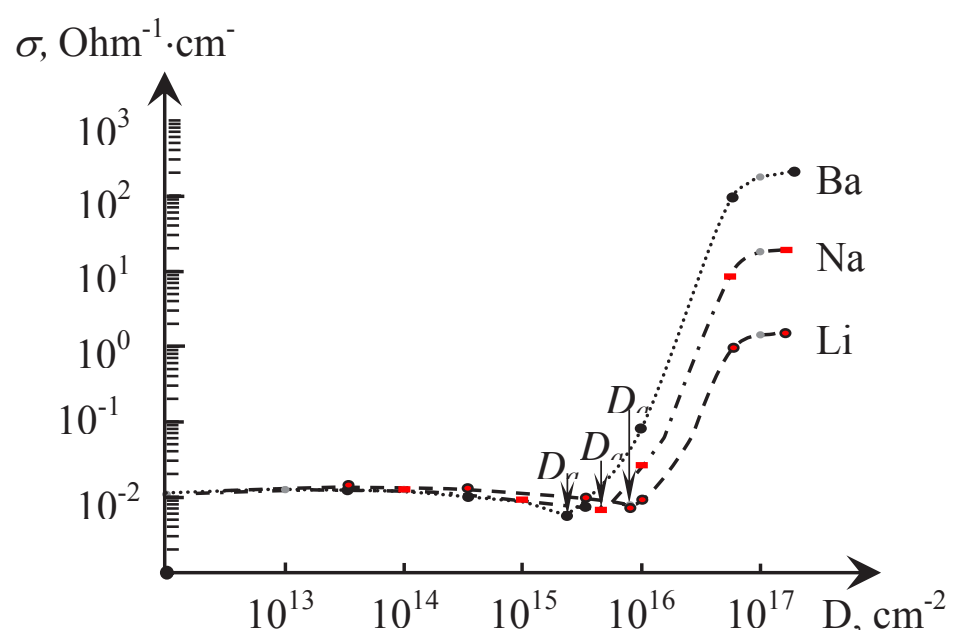

Fig.3. Dependences of the specific electrical conductivity $\sigma$ of the Si (111) surface on the dose of implantation of ions $\left(\mathrm{Li}^{+}, \mathrm{Na}^{+}\right.$, and $\left.\mathrm{Ba}^{+}\right)$with an energy of $1 \mathrm{keV}[4]$. 


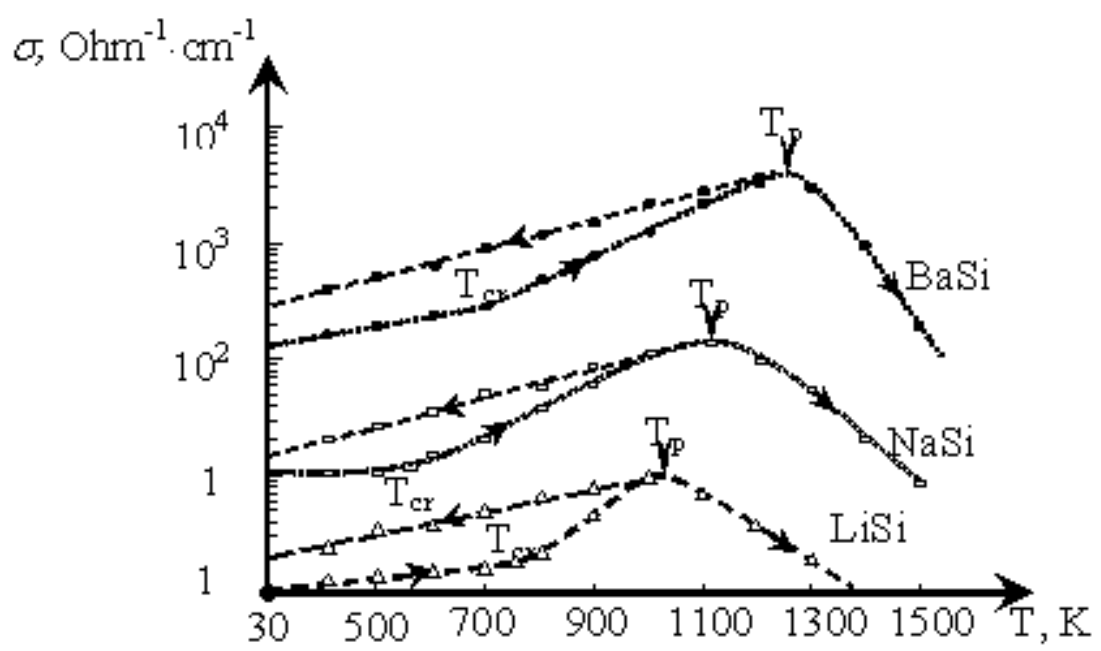

Fig.4. Dependences of the specific electrical conductivity $\sigma$ of the Si (111) surface implanted with ions $\left(\mathrm{Li}^{+}, \mathrm{Na}^{+}\right.$, and $\left.\mathrm{Ba}^{+}\right)$on the annealing temperature [4].

Figure 4 shows the dependences of the specific electrical conductivity $\sigma$ of the $\mathrm{Si}$ (111) surface implanted with $\mathrm{Li}^{+}, \mathrm{Na}^{+}$, and $\mathrm{Ba}^{+}$ions with an energy of $1 \mathrm{keV}$ with a dose of $2 \cdot 10^{17}$ $\mathrm{cm}^{-2}$ on the temperature of subsequent annealing [6]. It can be seen from the figure that, starting from the temperature $\mathrm{T}_{\mathrm{cr}}$, which corresponds to the recrystallization of the implanted area, a sharp increase in $\sigma$ is observed. In our opinion, at $\mathrm{T}=\mathrm{T}_{\mathrm{cr}}$, the formation of nanoscale films of $\mathrm{LiSi}, \mathrm{NaSi}, \mathrm{BaSi}$ is observed.

At a temperature $\mathrm{T}>\mathrm{T}_{\mathrm{p}}$, the fracture of the silicide film $\sigma$ decreases. Evaluation of the thickness of the silicide film by the method of layer-by-layer Auger analysis showed that at an ion energy of $1 \mathrm{keV}$, the thickness of the films is $5-6 \mathrm{~nm}$ (or $50-60 \AA$ ). When the silicide films are cooled from $\mathrm{T}_{\mathrm{p}}$ to $300 \mathrm{~K}$, the electrical conductivity of the silicide films decreases linearly, which is typical for degenerate semiconductors.

\section{Conclusion}

In this work, the optimal modes of formation of thin nanosized films of barium silicides and alkali elements are determined for the first time. It is shown that the thickness of the metal silicide films increases linearly with an increase in the energy of the implanted ions and, at fixed energy, increases with an increase in the dose as $\mathrm{D}^{1 / 2}$.

It has been established that implantation of $\mathrm{Ba}^{+}, \mathrm{Na}^{+}$, and $\mathrm{Li}^{+}$ions with an energy of 1 $\mathrm{keV}$ (regardless of the type of ions) up to a dose of $8 \cdot 10^{14} \mathrm{~cm}^{-2}$ practically does not lead to a change in the specific electrical conductivity of the n-Si (111) surface. With a further increase in the dose of implanted ions, a sharp increase in $\sigma$ is observed up to $\mathrm{D}=10^{17} \mathrm{~cm}^{-2}$, then saturation occurs.

\section{References}

1. Schuller B., Carius R., Mantl S. Optical and structural properties of $\beta$-FeSi $i_{2}$ precipitate layers in silicon, J. Appl. Phys. 94, No (1), pp. 207-211. DOI: 10.1063/1.1576902.(2003). 
2. Shteyman E.A., Vdovin V.I., Izotov A.N., Parkhomen $\neg$ ko YU.N., Borun A.F. Fotolyuminestsentsiya i strukturnyye defekty sloyev kremniya, implantirovannykh ionami zheleza, Zhurnal Fizika tverdogo tela,46,(1), pp. 26-30. (2004).

3. Maeda Y., Terai Y., Itakura M., Kuwano N., Thin Solid Films. (461). pp. 160-164. (2004).

4. Normuradov M.T., Risbaev A.S., Khujaniyozov J.B., Normuradov D.A. Structure of MeSi Silicide Films (Me: Li, Rb, K and Cs) According to Electron Microscopy Data and the Diffraction of Slow Electrons, Journal of Surface Investigation, 14, (5), pp. 1066-1071. DOI: 10.1134/S 1027451020050365.(2020).

5. Rysbaev A.S., Normurodov M.T., Rakhimov A.M., Tursunmetova Z.A., Tashatov A.K. High-Sensitivity Temperature Sensor on the Basis of Single-Crystal Si(111) Implanted from Multiple Directions with $P^{+}$and $B^{+}$Ionn, Journal of Surface Investigation, 14, No (6), pp. 1168-1173. DOI: 10.1134/S1027451017020318.(2020).

6. Rysbaev A.S., Khuzhaniyazov Z.B., Rakhimov A.M., Bekpulatov I.R. Formation of nanosize silicides films on the Si(111) and Si(100) surfaces by low-energy ion implantation, Technical Physics, 59, (10), pp. 1526-1530. DOI: 10.1134/S1063784214100272.( 2014).

7. Rysbaev A.S., Tashatov A.K., Dzhuraev S.X., Arzikulov G., Nasriddinov S.S. On new two-dimensional structures produced on the Si (111) and Si (100) surface upon molecular-beam epitaxy of cobalt and silicon. Journal of Surface Investigation, 5, (6), pp. 1193-1196. DOI: 10.1134/ S1027451011100193.( 2011).

8. Risbaev A.S., Khujaniyazov J.B., Bekpulatov I.R., Rakhimov A.M. Method for additional purification of the surface of Si(111) single crystal, Journal of Surface Investigation, 11, (5), pp. 994-999. DOI: 10.1134/ S1027451017050135.(2017).

9. Kamilov T.S., Rysbaev A.S., Klechkovskaya V.V., Orekhov A.S., Igamov B.D., Bekpulatov I.R. The Influence of Structural Defects in Silicon on the Formation of Photosensitive $\mathrm{Mn}_{4} \mathrm{Si}_{7} \mathrm{Si}\left\langle\mathrm{Mn} \mathcal{L}_{-\mathrm{Mn}} \mathrm{Si}_{7}\right.$ and $\mathrm{Mn}_{4} \mathrm{Si}_{7}-\mathrm{Si}\left\langle\mathrm{Mn} \mathcal{L}_{-M}\right.$ Heterostructures. Applied Solar Energy (English translation of Geliotekhnika), 55, (6), pp. 380-384. DOI: 10.3103/ S0003701X19060057. (2019).

10. Umirzakov B.E., Ashurov R.K., Donaev S.B. The Morphology and Electronic Properties of Si Nanoscale Structures on a CaF ${ }_{2}$ Surface. Technical Physics, 64, (2), pp. 232-235. DOI:10.1134/ S1063784219020269. (2019).

11. Rysbaev A.S., Khuzhaniyazov Z.B., Normuradov M.T., Rakhimov A.M., Bekpulatov I.R. Peculiarities of the electron structure of nanosized ion-implanted layers in silicon. Technical Physics, 59, (11), pp. 1705-1710. DOI:10.1134/S106378421411022X. (2014).

12. Umirzakov B.E., Donaev S.B. On the creation of ordered nuclei by ion bombardment

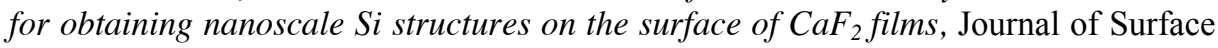
Investigation, 11, (4), pp. 746-748. https://doi: 10.1134/S1027451017040139. (2017).

13. Donaev S.B., Djurabekova F., Tashmukhamedova D.A. and Umirzakov B.E. Formation of nanodimensional structures on surfaces of GaAs and Si by means of ion implantation. Physica status solidi 12 (1-2), pp.89-93. https://doi.org/10.1002/pssc.201400156. (2015).

14. Rysbaev A.S., Khujaniyozov J.B., Normuradov M.T., Igamov B.D., Abraeva S.T. Theoretical Explanation of the Effect of a Decrease in the Si(111) Plasmon Energy during the Implantation of Ions with a Large Dose, Journal of Surface Investigation, 14, (4), pp. 816-822. https://doi.org/10.1134/S102745102004031X. (2020).

15. Rysbaev A.S. Variation of the secondary-emission properties of the surface of single crystals of silicon under conditions of ion implantation and subsequent annealing. Radiotekhnika i Elektronika, 46, (7), pp. 883-885. (2001). 
16. Umirzakov B.E., Tashmukhamedova D.A., Ruzibaeva M.K., Donaev S.B., Mavlyanov B.B. Analysis of the structure and properties of heterostructured nanofilms prepared by epitaxy and ion implantation methods. Technical Physics, , 58, (9), pp. 1383-1386. https://doi.org/10.1134/S1063784213090260. (2013).

17. Umirzakov B.E., Tashmukhamedova D.A., Ruzibaeva M.K., Djurabekova F.G., Danaev S.B. Investigation of change of the composition and structure of the $\mathrm{CaF}_{2} / \mathrm{Si}$ films surface at the low-energy bombardment. Nuclear Instruments and Methods in Physics Research, Section B: Beam Interactions with Materials and Atoms, (326), pp. 322-325.( 2014).

18. Rysbaev A.S., Normuradov M.T., Yuldashev Yu.Yu., Nasriddinov S.S. The effect of implantation of low-energy ions on the density of states of valence electrons in silicon, Radiotekhnika i Elektronika, 42, (2), pp. 240-242. (1997).

19. Donaev S.B., Tashatov A.K., Umirzakov B.E. Effect of $\mathrm{Ar}^{+}$-ion bombardment on the composition and structure of the surface of $\mathrm{CoSi}_{2} / \mathrm{Si}(111)$ nanofilms. Journal of Surface Investigation, 9, (2), pp. 406-409. https://doi.org/10.1134/S1027451015020263. (2015)

20. Isakhanov Z.A., Umirzakov Y.E., Ruzibaeva M.K., Donaev S.B. Effect of the $\mathrm{O}_{2}{ }^{+}$-ion bombardment on the TiN composition and structure. Technical Physics. 60, No (2), pp. 313-315. https://doi.org/10.1134/S1063784215020097. (2015). 